\title{
EGFR-RAD51 gene fusion NSCLC responsiveness to different generation EGFR-TKIs: two cases and review of the literature
}

\author{
Alessandro Di Federico ${ }^{1,2} \wedge$, Marco Filetti ${ }^{3}$, Arianna Palladinii ${ }^{2,4}$, Raffaele Giusti ${ }^{3}$, Marta Piras $^{3}$, \\ Andrea De Giglio ${ }^{1,2}$, Andrea Ardizzoni ${ }^{1,2}$, Francesco Gelsomino ${ }^{1,2} \wedge$ \\ ${ }^{1}$ Division of Medical Oncology, IRCCS Azienda Ospedaliero-Universitaria di Bologna, Bologna, Italy; ${ }^{2}$ Department of Experimental, Diagnostic \\ and Specialty Medicine (DIMES), University of Bologna, Bologna, Italy; ${ }^{3}$ Medical Oncology Unit, Sapienza University of Rome, Rome, Italy; \\ ${ }^{4}$ Department of Pharmacy and Biotechnology, University of Bologna, Bologna, Italy \\ Correspondence to: Francesco Gelsomino. Division of Medical Oncology, IRCCS Azienda Ospedaliero-Universitaria di Bologna, 40138 Bologna, Italy. \\ Email: francesco_gelsomino@aosp.bo.it; francesco.gelsomino3@unibo.it.
}

\begin{abstract}
Epidermal growth factor receptor $(E G F R)$ gene fusions represent an extremely rare aberration, occurring in approximately $0.05-0.13 \%$ non-small cell lung cancer (NSCLC) patients. RAD51 is the most frequently involved partner gene in EGFR fusions, but other fusion partner genes have been described. To date, a considerable number of next-generation sequencing (NGS) panels still cannot detect these alterations due to the position of the breakpoint site, mainly involving intron 24 of EGFR. Current evidences show that such gene alteration is more likely to occur in lung adenocarcinomas of young, female, non-smoker patients. Also, brain metastases are frequently reported in these patients. Only very few cases in literature described clinical characteristics and outcomes of patients harboring EGFR gene fusions, reporting responses to 1 st generation EGFR tyrosine kinase inhibitors (TKIs). Herein, we report the case of two young nonsmoker females with metastatic NSCLC harboring EGFR-RADS1 gene fusion, detected by FoundationOne DX1 assay, who responded to EGFR TKIs. The first patient initially received erlotinib, then switched to osimertinib for renal toxicity, while the second was treated with gefitinib. This is, to our knowledge, the first report describing response to the 3rd EGFR TKI osimertinib. Our experience highlights the need of a broader molecular profiling in young or never smoker NSCLC patients without detectable molecular aberration using standard NGS panels. Finally, further studies to assess the real prevalence of EGFR gene fusions and their spectrum of sensitivity to different EGFR TKIs are needed.
\end{abstract}

Keywords: Epidermal growth factor receptor (EGFR) gene fusion; RAD51; non-small cell lung cancer (NSCLC); tyrosine kinase inhibitor (TKI); case report

Submitted Nov 08, 2021. Accepted for publication Jan 14, 2022.

doi: $10.21037 /$ tlcr-21-888

View this article at: https://dx.doi.org/10.21037/tlcr-21-888

\section{Introduction}

Epidermal growth factor receptor (EGFR) gene mutations account for around $15 \%$ of non-small cell lung cancer (NSCLC) in Caucasian patients (1). They most commonly occur as in-frame deletion in exon 19 or point mutation in exon 21 (L858R), conferring constitutive activation of EGFR tyrosine kinase domain. Following the implementation of EGFR tyrosine kinase inhibitors (TKIs) as the gold standard first-line therapy in this molecularly distinct subgroup of advanced NSCLC patients, testing for EGFR mutations has become standard practice, especially in non-squamous histology (1-5). The recent introduction of different nextgeneration sequencing (NGS) platforms has improved the turnaround time and widened the molecular testing of NSCLC, allowing to identify rarer genetic alterations capable of driving cancer proliferation. As part of them,

^ ORCID: Alessandro Di Federico, 0000-0001-8877-4315; Francesco Gelsomino, 0000-0002-9204-1728. 
EGFR gene fusions represent an extremely rare finding, with a prevalence of around $0.05-0.13 \%$ (6). The most frequent EGFR fusion partner gene is RAD51, but PURB, ANXA2, $K I F 5 B$ and SEPT14 have been reported as well (7-9). $R A D 51$ encodes for a protein involved in DNA-damage response and repair (DDR) mechanism and homologous recombination (HR). Breakpoints involve intron 24 of $E G F R$ and intron 3 of $R A D 51$, resulting in the fusion of EGFR exons 1-24 and RAD51 exons 4-10. Interestingly, all NSCLC patients with EGFR-RAD51 fusion responded to erlotinib (6). Few additional case reports described the role of EGFR-RAD51 fusion in NSCLC patients, confirming its sensitivity to standard EGFR-TKIs (9-11). We present the following case series in accordance with the CARE reporting checklist (available at https://tlcr.amegroups.com/ article/view/10.21037/tlcr-21-888/rc).

\section{Case presentation}

\section{Case \#1}

A 29-year-old non-smoker female was diagnosed in October 2019 with metastatic adenocarcinoma of the left lung (TTF-1+, Napsin-A+) following diagnostic assessment for dry cough and shoulder pain. Computed tomography (CT) scan showed secondary lesions involving lungs, bones, brain, soft tissues and lymph nodes. Programmed death ligand-1 (PD-L1) expression (clone SP263, Ventana) was negative (tumor proportion score, TPS $<1 \%$ ), and the baseline NGS performed on a nodal biopsy with the Oncomine Focus Assay-ThermoFisher Scientific (Kit RUO; Pleasanton, CA, USA) did not show gene aberrations.

The patient received the combination of chemotherapy (cisplatin $75 \mathrm{mg} / \mathrm{m}^{2}$ plus pemetrexed $500 \mathrm{mg} / \mathrm{m}^{2}$ every 3 weeks) and immunotherapy (pembrolizumab $200 \mathrm{mg}$ every 3 weeks) as first-line treatment, obtaining clinical benefit and an objective partial response (PR) at CT scan imaging performed after the completion of induction phase (4 cycles). Maintenance treatment with pembrolizumab and pemetrexed was then started. A CT scan performed after 4 cycles showed progressive disease (PD) on lungs, brain and lymph nodes. Considering the maintained good performance status and the absence of symptomatic disease, the treatment was continued beyond progression and wholebrain radiation therapy (20 Gy/5 fractions) was performed.

The patient underwent a new biopsy on a left shoulder muscle metastatic nodule and a new molecular analysis was attempted using the same NGS panel. Again, no genetic aberration was detected. However, taking into account patient's young age and non-smoking status, a new biopsy on mediastinal lymph node was performed to obtain representative tumor tissue for FoundationOne DX1 panel which detected the presence of an EGFRRAD 1 gene fusion. Concurrent cancer-related alterations were also found in the following genes: adenomatous polyposis coli (APC) loss; SMAD family member 4 (SMAD4_K340E); ataxia telangiectasia and Rad3-related protein (ATR_E1685); phosphatidylinositol4,5-bisphosphate 3 -kinase catalytic subunit alpha (PIK3CA, H450_P458del). The tumor mutational burden (TMB) was $10.09 \mathrm{Mut} / \mathrm{Mb}$.

In light of existing literature, first-generation EGFR-TKI erlotinib (150 mg daily, then reduced to $100 \mathrm{mg}$ daily due to recurrent grade 2 hyperbilirubinemia) was administered leading to a PR on all tumor sites, including brain, after only three weeks from treatment initiation (Figure 1). A progressive increase of serum creatinine $(1.97 \mathrm{mg} / \mathrm{dL})$ and worsening of glomerular filtration rate $(33 \mathrm{~mL} / \mathrm{min}$ according to Chronic Kidney Disease Epidemiology Collaboration, CDK-EPI) led to erlotinib discontinuation after two months of treatment. Renal biopsy showed severe chronic tubulointerstitial nephritis, consistent with karyomegalic nephropathy, probably related to prior chemoimmunotherapy. The third generation TKI osimertinib (80 $\mathrm{mg}$ daily) was then administered, with further tumor response at the subsequent restaging imaging. After 12 months from the beginning of EGFR-TKI, the treatment is still ongoing.

\section{Case \#2}

In August 2019, a 37-year-old never-smoker woman was referred to the emergency room complaining of worsening dyspnea. The patient had no medical history except for autoimmune hypothyroidism. Upon admission, a chest CT scan showed massive pleural effusion with multiple pulmonary nodules spread to both lungs. Pleural effusion drainage and lung biopsy were performed. Based on histological examination and immunohistochemistry (TTF-1+, Napsin-A+, and cytokeratin $7+$ ) assays the diagnosis was suggestive of pulmonary adenocarcinoma with mucinous pattern, PD-L1 (clone 22C3 pharmDx) positive (TPS 20\%). Molecular analysis by using FoundationOne DX1 panel allowed to detect EGFR-RAD51 fusion and tumor protein P53 (TP53_ E294) mutation; no other known cancer-related gene alterations were identified. The TMB was $2 \mathrm{Mut} / \mathrm{Mb}$. 

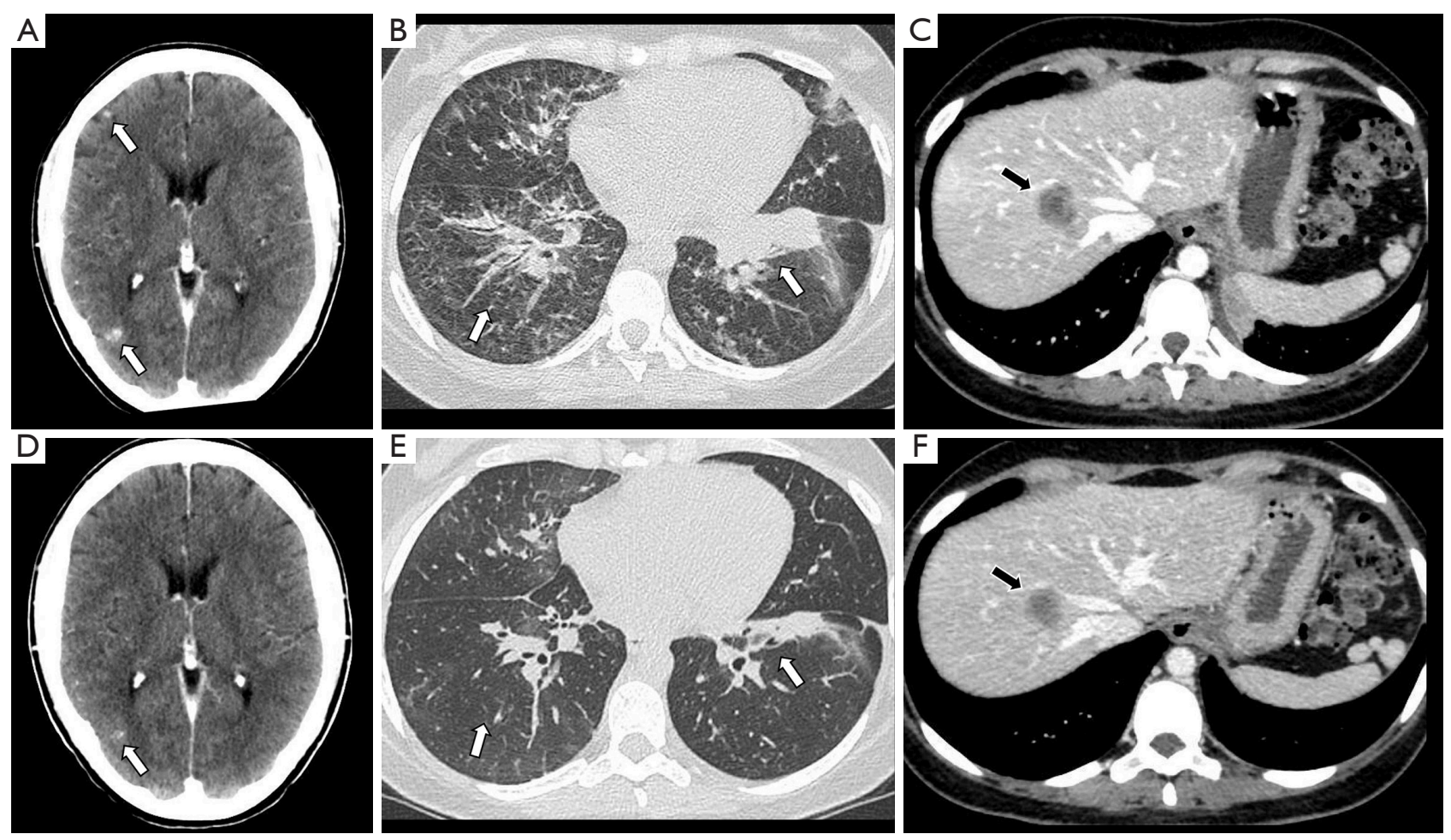

Figure 1 CT scans of case \#1 performed before the initiation of the therapy with erlotinib (A-C) and after three weeks of treatment (D-F), showing PR on brain, lungs and liver lesions, see arrows. CT, computed tomography; PR, partial response.
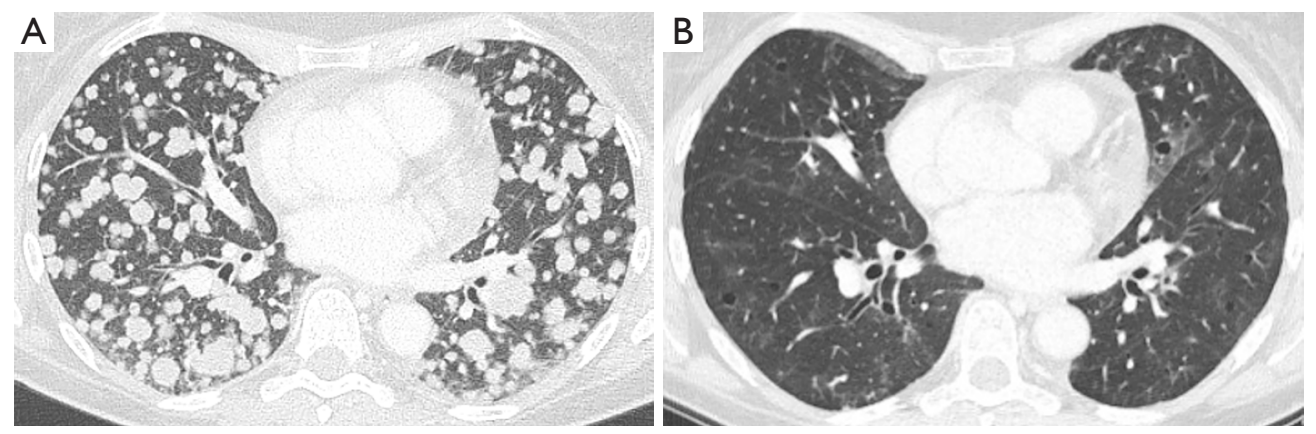

Figure 2 CT scans of case \#2 performed before the initiation of the therapy with gefitinib (A) and after three months of treatment (B), showing CR. CT, computed tomography; CR, complete response.

The patient, therefore, started first-line treatment with first-generation EGFR-TKI gefitinib. Within few weeks, dyspnea improved considerably, and after three months a CT scan showed a complete response (CR) (Figure 2). The treatment was well tolerated, and no serious adverse event occurred (grade 2 skin rash and grade 1 diarrhea).

Unfortunately, after one year, in September 2020 a new CT scan showed PD (bilateral lung and single brain metastasis). The patient had chest pain and dyspnea.
No new molecular assay on tissue or liquid re-biopsy by FoundationOne DX1 panel was performed because it was not available at that time. A customized gene sequencing panel was performed on liquid biopsy that confirmed the presence of TP53 mutation along with hepatocyte growth factor $(H G F)$ amplification. Single brain lesion was treated by stereotactic radiotherapy (27 Gy/3 fractions). Therefore, the patient started chemo-immunotherapy (cisplatin $75 \mathrm{mg} / \mathrm{m}^{2}$ plus pemetrexed $500 \mathrm{mg} / \mathrm{m}^{2}$ plus pembrolizumab 
$200 \mathrm{mg}$ every 3 weeks) as second-line therapy. Clinical improvement in respiratory symptoms was observed during the first month from the beginning of the treatment. The first radiological assessment documented a PR, with a reduction of pulmonary nodules and pleural effusion. To date, the patient continues the treatment with excellent tolerance (only grade 1 asthenia and no immune-related adverse event) and no evidence of disease progression.

All procedures performed in this study were in accordance with the ethical standards of the institutional and/or national research committee(s) and with the Helsinki Declaration (as revised in 2013). Written informed consent was obtained from the patients for publication of this case series and accompanying images. A copy of the written consent is available for review by the editorial office of this journal.

\section{Discussion}

Konduri et al. (6) first described EGFR-RAD 51 gene fusion in NSCLC, reporting a case series comprising four patients with NSCLC harboring this extremely rare aberration. They demonstrated in preclinical studies that EGFR-RAD51 fusion creates active dimers and activates the mitogenactivated protein kinase (MAPK) and phosphoinositide3-kinase/protein kinase B/Akt (PI3K/AKT) pathways to mediate downstream signaling. Surprisingly, EGFR$R A D 51$ fusion lacks several autophosphorylation sites in the C-terminal tail of EGFR, which represent docking sites for adaptor proteins and play an important role in EGFR proliferation signaling. The preserved ability to activate downstream pathways of EGFR-RADS1 fusion gene may thus be explained by the presence of tyrosine 845 , another phosphorylation site within the kinase domain that is necessary for EGFR function and transformation in NSCLC (6). Moreover, the lack of tyrosine 1045, a binding site to mediate $E G F R$ degradation, provides higher stability and lower degradation rate compared to $E G F R$ wild type receptor.

EGFR-RAD 1 gene fusion involves EGFR exons 1-24 and $R A D 51$ exons 4-10 through breakpoints in EGFR intron 24 and $R A D 51$ intron 3 (6). However, routinely used genetic assays usually search for aberrations between exons 18 and 21, which represent by far the most commonly altered sites in the EGFR gene. This explains why EGFR$R A D 51$ fusion is often undetected.

To our knowledge, a total of 10 cases of patients harboring EGFR-RAD 51 fusion are reported in literature, included our two patients (6,9-12). All of them had adenocarcinoma histology. The majority were females $(70 \%)$, young (median age: 36.5 years; range, $21-$ 62 years), never or former light smokers $(70 \%)$, and had brain metastases (70\%). Coexisting tumor gene alterations and further patients' details are summarized in Table 1. Eight out of 10 patients received an EGFR-TKI as first- or further lines of treatment. All EGFR-TKIs

Table 1 Characteristics of patients harboring the EGFR-RAD 1 gene fusion

\begin{tabular}{|c|c|c|c|c|c|c|c|c|c|}
\hline $\begin{array}{l}\text { Patient } \\
\text { No. }\end{array}$ & Ethnicity & $\begin{array}{l}\text { Age/ } \\
\text { gender }\end{array}$ & $\begin{array}{l}\text { Smoking } \\
\text { status }\end{array}$ & Histology & Disease sites & Other genetic alterations (including VUS) & $\begin{array}{c}\text { Prior } \\
\text { treatment }\end{array}$ & $\begin{array}{c}\text { EGFR } \\
\text { TKI }\end{array}$ & $\begin{array}{l}\text { Best } \\
\text { response }\end{array}$ \\
\hline 1 & Caucasian & $29 / F$ & Never & ADC & $\begin{array}{l}\text { Lungs; liver; } \\
\text { bones; brain; } \\
\text { soft tissues; } \\
\text { lymph nodes }\end{array}$ & $\begin{array}{l}\text { APC loss; SMAD4 K340E; ATR E1685*; } \\
\text { PIK3CA H450_P458del; ERCC4 } \\
\text { amplification; CREBBP amplification; } \\
\text { MSH6 T1243S; CYP17A1 F384I; } \\
\text { INPP4B A52S; PTCH1 V619I; EGFR } \\
\text { H1156P; FANCA V230I; WHSC1 S808C; } \\
\text { ATR H1294Y; ATM D894H; JAK3 E183Q }\end{array}$ & $\begin{array}{l}\text { PEM/MTA/ } \\
\text { CDDP }\end{array}$ & $\begin{array}{l}\text { ERL } \\
\text { followed } \\
\text { by OSI }\end{array}$ & PR \\
\hline 2 & Caucasian & $37 / F$ & Never & ADC & $\begin{array}{l}\text { Pleura; lungs; } \\
\text { lymph nodes }\end{array}$ & $\begin{array}{l}\text { TP53 E294 DDR1 P501L; EPHB1 } \\
\text { P419S; RPTOR S637F; GRM3 A291T; } \\
\text { SMO E740G; HGF amplification (at PD) }\end{array}$ & None & GEF & CR \\
\hline $3(6)$ & Asian & $35 / F$ & Never & ADC & $\begin{array}{l}\text { Bone; brain; } \\
\text { adrenal } \\
\text { gland breast; } \\
\text { peritoneum; eye; } \\
\text { lymph nodes }\end{array}$ & $\begin{array}{l}\text { CDKN2A loss; CDKN2B loss; } M Y C \\
\text { amplification }\end{array}$ & None & ERL & PR \\
\hline
\end{tabular}

Table 1 (continued) 
Table 1 (continued)

\begin{tabular}{|c|c|c|c|c|c|c|c|c|c|}
\hline $\begin{array}{l}\text { Patient } \\
\text { No. }\end{array}$ & Ethnicity & $\begin{array}{l}\text { Age/ } \\
\text { gender }\end{array}$ & $\begin{array}{l}\text { Smoking } \\
\text { status }\end{array}$ & Histology & Disease sites & Other genetic alterations (including VUS) & $\begin{array}{l}\text { Prior } \\
\text { treatment }\end{array}$ & $\begin{array}{l}\text { EGFR } \\
\text { TKI }\end{array}$ & $\begin{array}{l}\text { Best } \\
\text { response }\end{array}$ \\
\hline $4(6)$ & Caucasian & $21 / F$ & Current & ADC & $\begin{array}{l}\text { Bone; brain; } \\
\text { lymph nodes }\end{array}$ & $\begin{array}{l}\text { CTNNB1 T41A; RANBP2 T951M; } \\
\text { CDKN2B loss }\end{array}$ & None & ERL & PR \\
\hline $5(6)$ & Caucasian & $38 / \mathrm{M}$ & Former & ADC & $\begin{array}{l}\text { Lungs; pleura; } \\
\text { bone; } \\
\text { lymph nodes }\end{array}$ & $\begin{array}{l}\text { RBM10 S570fs*133; CHD4 D316H; } \\
\text { MYC amplification; MCL1 amplification; } \\
\text { IKBKE amplification; PIK3C2B } \\
\text { amplification; MDM4 amplification }\end{array}$ & MTA/CDDP & ERL & PR \\
\hline $6(6)$ & Caucasian & $60 / F$ & Never & ADC & $\begin{array}{c}\text { Brain; } \\
\text { lymph nodes }\end{array}$ & $\begin{array}{l}\text { GRIN2A R1318W; ATR Q2408*; ARID1A } \\
\text { P1484fs }{ }^{*} 10 ; \text { FGF3 amplification; FGF4 } \\
\text { amplification; CDKN2A loss; PDCD1LG2 } \\
\text { amplification; CCND1 amplification; } \\
\text { CD274 amplification; FGF19 } \\
\text { amplification; EMSY amplification; } \\
\text { HGF amplification; JAK2 amplification; } \\
\text { CDKN2B loss }\end{array}$ & $\begin{array}{l}\text { MTA } \\
\text { CBDCA }\end{array}$ & None & PR \\
\hline $7(9)$ & Asian & $36 / F$ & Never & ADC & $\begin{array}{l}\text { Lungs; bone; } \\
\text { brain; pleura; } \\
\text { pericardium }\end{array}$ & $\begin{array}{l}\text { EGFR-ANXA2 fusion; } A T R \text { exon } 44 \\
\text { mutation; BRCA2 exon } 19 \text { mutation }\end{array}$ & $\begin{array}{l}\text { LOBA/MTA/ } \\
\text { TEM/BEV }\end{array}$ & None & PR \\
\hline $8(10)$ & Caucasian & $62 / F$ & Never & ADC & Brain; pleura & N.A. & $\begin{array}{c}\text { 1st-L: } \\
\text { BEV/MTA } \\
\text { CBDCA; } \\
\text { 2nd-L: } \\
\text { NIVO; 3rd-L: } \\
\text { TAX }\end{array}$ & AFA & PR \\
\hline $9(11)$ & Asian & $26 / \mathrm{M}$ & Never & ADC & Pleura & TP53 G244D & MTA/CDDP & $\mathrm{ICO}$ & PR \\
\hline
\end{tabular}

EGFR, epidermal growth factor receptor; VUS, variants of unknown significance; EGFR-TKI, epidermal growth factor receptor tyrosine kinase inhibitor; F, female; ADC, adenocarcinoma; APC, adenomatous polyposis coli; SMAD4, SMAD family member 4; ATR, ataxia telangiectasia and Rad3-related protein; PIK3CA, phosphatidylinositol-4,5-bisphosphate 3-kinase catalytic subunit alpha; ERCC4, ERCC Excision Repair 4; CREBBP, cyclic adenosine monophosphate response element binding protein; MSH6, MutS Homolog 6; CYP17A1, cytochrome P450 family 17 subfamily A member 1; INPP4B, inositol polyphosphate-4-phosphatase type II B; PTCH1, protein patched homolog 1; FANCA, Fanconi anaemia, complementation group A; WHSC1, Wolf-Hirschhorn syndrome candidate 1; ATM, ataxiatelangiectasia mutated; JAK3, Janus Kinase 3; PEM, pembrolizumab; MTA, pemetrexed; CDDP, cisplatin; ERL, erlotinib; OSI, osimertinib; $\mathrm{PR}$, partial response; TP53, tumor protein P53; DDR1, Discoidin Domain Receptor Tyrosine Kinase 1; EPHB1, Ephrin type-B receptor 1; RPTOR, Regulatory Associated Protein Of MTOR Complex 1; GRM3, Glutamate Metabotropic Receptor 3; SMO, Smoothened homolog precursor; HGF, hepatocyte growth factor; PD, progressive disease; GEF, gefitinib; CR, complete response; CDKN2A, cyclin dependent kinase inhibitor 2A; CDKN2B, cyclin dependent kinase inhibitor 2B; MYC, MYC Proto-Oncogene; CTNNB1, Catenin (Cadherin-Associated Protein) Beta 1; RANBP2, RAN Binding Protein 2; M, male; RBM10, RNA Binding Motif Protein 10; CHD4, Chromodomain Helicase DNA Binding Protein 4; MCL1, Myeloid Cell Leukemia Sequence 1; IKBKE, Inhibitor Of Nuclear Factor Kappa B Kinase Subunit Epsilon; PIK3C2B, Phosphatidylinositol-4-Phosphate 3-Kinase Catalytic Subunit Type 2 Beta; MDM4, Mouse Double Minute 4; GRIN2A, Glutamate Ionotropic Receptor NMDA Type Subunit 2A; ARID1A, AT-rich interactive domain-containing protein 1A; FGF3, fibroblast growth factor 3; FGF4, fibroblast growth factor 4; PDCD1LG2, Programmed Cell Death 1 Ligand 2; CCND1, Cyclin D1; CD274, Programmed Cell Death 1 Ligand 1; FGF19, fibroblast growth factor 19; EMSY, EMSY Transcriptional Repressor, BRCA2 Interacting; JAK2, Janus Kinase 2; CBDCA, carboplatin; ANXA2, Annexin A2; BRCA2, Breast And Ovarian Cancer Susceptibility Protein 2; LOBA, lobaplatin; TEM, temozolomide; BEV, bevacizumab; N.A, not available; L, line; NIVO, nivolumab; TAX, docetaxel; AFA, afatinib; ICO, icotinib. 
led to radiological tumor response (7 PRs $+1 \mathrm{CR})$. The remaining 2 patients were treated with chemotherapy and obtained a PR. In preclinical models, EGFR-RAD51 cell lines treated with several EGFR-TKIs (erlotinib, afatinib and osimertinib), as well as EGFR monoclonal antibody (cetuximab), showed significant inhibition of tumor cell growth (6). However, in clinical practice, no previous data reported the sensitivity of NSCLC patients harboring EGFR-RAD 51 fusion to third-generation, irreversible EGFR-TKI osimertinib. The therapeutic implication of the involvement of $R A D 51$ as fusion partner gene has never been explored, but the role of poly-ADP-ribose polymerase inhibitors (PARPi) and other agents acting on DDR genes warrant investigation as therapeutic options for these patients, aside from EGFR-TKIs.

The current case series represents the first documented evidence of clinical activity of osimertinib and gefitinib in two NSCLC patients harboring EGFR-RAD51 gene fusion. Considering its great intracranial activity and tolerability, the 3rd generation EGFR inhibitor could represent the preferred option, especially in case of brain metastasis. This work highlights the importance of employing genetic assays broad-panel NGS assays when standard panels do not show gene aberrations, especially in case of young and nonsmoker patients with adenocarcinoma histology. Further studies and a routine use of wider molecular profiling would allow to assess the real prevalence of the EGFR-RAD51 fusion, the outcome of patients treated with EGFR-TKIs, and the possible clinical and therapeutic implication of $R A D 51$ as fusion partner gene.

\section{Acknowledgments}

Funding: This article was supported by the Cassa di Risparmio in Bologna (CaRisBo) Foundation (grant No. 2019-0543 project to Principal Investigator Professor PierLuigi Lollini).

\section{Footnote}

Reporting Checklist: The authors have completed the CARE reporting checklist. Available at https://tlcr.amegroups.com/ article/view/10.21037/tlcr-21-888/rc

Peer Review File: Available at https://tlcr.amegroups.com/ article/view/10.21037/tlcr-21-888/prf

Conflicts of Interest: All authors have completed the
ICMJE uniform disclosure form (available at https://tlcr. amegroups.com/article/view/10.21037/tlcr-21-888/coif). AA reports research grants from Celgene, BMS, Ipsen, Roche; honoraria for advisory board participation from BMS, MSD, ROCHE, AstraZeneca, Eli-Lilly. FG reports personal fees from AstraZeneca and honoraria for advisory board participation from Eli-Lilly. The other authors have no conflicts of interest to declare.

Ethical Statement: The authors are accountable for all aspects of the work in ensuring that questions related to the accuracy or integrity of any part of the work are appropriately investigated and resolved. All procedures performed in this study were in accordance with the ethical standards of the institutional and/or national research committee(s) and with the Helsinki Declaration (as revised in 2013). Written informed consent was obtained from the patients for publication of this case series and accompanying images. A copy of the written consent is available for review by the editorial office of this journal.

Open Access Statement: This is an Open Access article distributed in accordance with the Creative Commons Attribution-NonCommercial-NoDerivs 4.0 International License (CC BY-NC-ND 4.0), which permits the noncommercial replication and distribution of the article with the strict proviso that no changes or edits are made and the original work is properly cited (including links to both the formal publication through the relevant DOI and the license). See: https://creativecommons.org/licenses/by-nc-nd/4.0/.

\section{References}

1. Rosell R, Moran T, Queralt C, et al. Screening for epidermal growth factor receptor mutations in lung cancer. N Engl J Med 2009;361:958-67.

2. Soria JC, Ohe Y, Vansteenkiste J, et al. Osimertinib in Untreated EGFR-Mutated Advanced Non-Small-Cell Lung Cancer. N Engl J Med 2018;378:113-25.

3. Yang JC, Sequist LV, Geater SL, et al. Clinical activity of afatinib in patients with advanced non-small-cell lung cancer harbouring uncommon EGFR mutations: a combined post-hoc analysis of LUX-Lung 2, LUX-Lung 3, and LUX-Lung 6. Lancet Oncol 2015;16:830-8.

4. Maemondo M, Inoue A, Kobayashi K, et al. Gefitinib or chemotherapy for non-small-cell lung cancer with mutated EGFR. N Engl J Med 2010;362:2380-8.

5. Rosell R, Carcereny E, Gervais R, et al. Erlotinib 
versus standard chemotherapy as first-line treatment for European patients with advanced EGFR mutation-positive non-small-cell lung cancer (EURTAC): a multicentre, open-label, randomised phase 3 trial. Lancet Oncol 2012;13:239-46.

6. Konduri K, Gallant JN, Chae YK, et al. EGFR Fusions as Novel Therapeutic Targets in Lung Cancer. Cancer Discov 2016;6:601-11.

7. Xu H, Shao C. KIF5B-EGFR Fusion: A Novel EGFR Mutation in Lung Adenocarcinoma. Onco Targets Ther 2020;13:8317-21.

8. Xu C, Wang WX, Chen Y, et al. Prevalence of EGFR gene fusions in a large cohort of Chinese patients with non-small cell lung cancer (NSCLC). J Clin Oncol 2018;36:e13538.

Cite this article as: Di Federico A, Filetti M, Palladini A, Giusti R, Piras M, De Giglio A, Ardizzoni A, Gelsomino F. EGFR-RAD51 gene fusion NSCLC responsiveness to different generation EGFR-TKIs: two cases and review of the literature. Transl Lung Cancer Res 2022;11(3):497-503. doi: 10.21037/ tlcr-21-888
9. Zhong R, Li H, Liu Y, et al. Chemotherapy combined with bevacizumab for the treatment of advanced lung adenocarcinoma cancer harboring EGFR-ANXA2, EGFRRAD51, ATR and BRCA2 mutations: A case report. Thorac Cancer 2020;11:456-60.

10. Raez LE, Pinto JA, Schrock AB, et al. EGFR-RAD51 Fusion: A Targetable Partnership Originated from the Tumor Evolution? J Thorac Oncol 2018;13:e33-4.

11. Guan Y, Song Z, Li Y, et al. Effectiveness of EGFR-TKIs in a Patient with Lung Adenocarcinoma Harboring an EGFR-RAD51 Fusion. Oncologist 2019;24:1027-30.

12. Zhu YC, Wang WX, Xu CW, et al. EGFR-RAD51 fusion variant in lung adenocarcinoma and response to erlotinib: A case report. Lung Cancer 2018;115:131-4. 